Article

\title{
Handle with Care-Microplastic Particles in Intestine Samples of Seals from German Waters
}

\author{
Carolin Philipp ${ }^{1}$, Bianca Unger ${ }^{1}$, Elke K. Fischer ${ }^{2}$, Joseph G. Schnitzler ${ }^{1}$ \\ and Ursula Siebert $1, * \mathbb{D}$ \\ 1 Institute for Terrestrial and Aquatic Wildlife Research, University of Veterinary Medicine Hannover, \\ Foundation, Werftstraße 6, 25761 Buesum, Germany; carolin.philipp@tiho-hannover.de (C.P.); \\ bianca.unger@tiho-hannover.de (B.U.); joseph.schnitzler@tiho-hannover.de (J.G.S.) \\ 2 Center for Earth System Research and Sustainability (CEN), University of Hamburg, Bundesstraße 55, \\ 20146 Hamburg, Germany; elke.fischer@uni-hamburg.de \\ * Correspondence: ursula.siebert@tiho-hannover.de
}

Received: 30 September 2020; Accepted: 10 December 2020; Published: 13 December 2020

\begin{abstract}
The Marine Strategy Framework Directive (MSFD) aims to reduce the marine debris burden in the marine environment by 2020 . This requires an assessment of the actual situation, which includes the occurrence as well as the caused impacts. Information on both is scarce when it comes to top predators like marine mammals and the burden of microplastic. This is hampered by the limited access to free ranging marine mammals for collecting samples, as well as sample handling. The present study investigated gastrointestinal tracts and faecal samples of harbour seals (Phoca vitulina) and grey seals (Halichoerus grypus) regularly occurring in the German North Sea and Baltic Sea with the aim of gaining information on the occurrence of microplastics. In total, 255 particles $\geq 100 \mu \mathrm{m}$ (70 fibres, 185 fragments) were found in exemplary ten intestine and nine faecal samples. The findings ranged from zero fibres and six fragments, up to 35 fibres and 55 fragments per sample. Additionally, this study established a protocol for sample handling, microplastic isolation $(\geq 100 \mu \mathrm{m})$ and quantification of gastrointestinal tracts and faecal samples of marine mammals with a low share of contamination. This approach helps to quantify the presence of microplastics in free-ranging marine mammals and is therefore applicable to assess the real burden of microplastic presence in the marine environment.
\end{abstract}

Keywords: microplastic; plastic isolation; plastic ingestion; gastrointestinal tract; marine mammals

\section{Introduction}

The challenging nature of marine debris pollution is well known [1]. Due to its widespread use, its specific characteristics and discard virtue, synthetic polymers, so-called "plastics" make up a high share of marine debris in our oceans [2-4]. Microplastic (MP) includes synthetic polymers in the form of particles smaller than $5 \mathrm{~mm}$ [5]. These particles originate either from large plastic items cracking down into smaller fragments due to various forces (secondary MP); or are intentionally produced in those small sizes (primary MP) [6-9]. The awareness of microplastics started back in the 1970s [10,11] but has only recently be brought more into focus of environmental research [12,13].

MPs were revealed to be ingested by organisms of lower trophic levels, and even a trophic transfer was detected [14-16]. A variety of international studies confirmed the presence of different sized plastic particles in the gastrointestinal tract (GIT) of various marine mammalian species [17-21].

Dealing with faunal samples implies the initial elimination of organic matter enclosing the particles; their detection otherwise would be obscured [22,23]. Therefore, the biogenic compounds have to be removed prior to further investigations in order to obtain convincing and reliable results [22,23]. 
Furthermore, it needs to be ensured that the risk of secondary contamination during sampling, storing and sample treatment is kept as low as possible. Contamination of samples might occur during their handling and origin, e.g., from storage containers, laboratory cloths, gloves and the working environment in general [24-28].

Previous studies already presented various digestion protocols of biota samples in recent years $[17,20,29]$. Enzymes were predominantly used to remove the organic matter $[23,30]$, in some cases acids or alkaline solutions were applied to digest organic remains $[26,29,31]$. Subsequently, MP identification techniques such as the staining and fluorescence microscopic approach $[32,33]$ and spectroscopic analyses like Fourier transform infrared (FT-IR) [34-36] or Raman spectroscopy are commonly used $[33,37,38]$. A combination of both methods is considered to be a reliable option regarding the identification of polymer compositions [39].

However, information on the presence of MP and its impacts on marine top predator species is scarce. Therefore, the present study focusses on establishing a protocol to isolate particles, evaluate potential contamination and propose a method to discriminate between MP and other particles in faecal and intestinal samples of seals in order to investigate the presence of MP in marine mammals in further research. Samples were taken from harbour seals (Phoca vitulina) and grey seals (Halichoerus grypus), which regularly occur in the North and Baltic Seas. This study was realised within the framework of the project "Assessment and implementation for long-term monitoring of pollution of diverse marine compartments and biota with marine litter" (Federal Environment Agency Germany), the aims of which were to optimize sample handling and to reduce the risk of secondary contamination for detecting microplastic particles in intestinal samples of marine mammals.

\section{Materials and Methods}

\subsection{Sample Collection}

The Institute for Terrestrial and Aquatic Wildlife Research (ITAW) at the University of Veterinary Medicine Hannover (Foundation Germany) regularly conducts necropsies of stranded, bycaught or euthanised marine mammals found along the coastline of the Federal State of Schleswig-Holstein, Germany $[19,40,41]$. These are predominantly the three species regularly occurring in German waters: harbour porpoise (Phocoena phocoena), harbour seal and grey seal.

Necropsy Sampling

Concerning microplastic analyses in the GIT of marine mammals, the rectum of harbour seals and grey seals has been sampled since 2014. Out of these, ten pinniped samples were used for this study. The caudal part of the rectum was tied off with a drawstring (Figure 1A). Subsequently, in a cranial direction, an $8-10 \mathrm{~cm}$ section was tied off. Both ends were cut off behind the drawstrings to prevent the loss of faeces (Figure 1B). With the help of metallic tweezers, the samples were transferred to cleaned and disinfected glass jars. Afterwards, the glass jars were stored at $-20{ }^{\circ} \mathrm{C}$ until further processing (Figure 1C,D).

\section{Sandbank Sampling}

In the course of a regularly conducted health monitoring of live animals at the Lorenzenplate [42], a tide-dependent submerged sandbank in the North Sea, further faecal samples of free-ranging harbour seals and grey seals have been collected since 2012. Out of these, nine faecal samples were analysed. No genetic analyses have been performed to distinguish between harbour seal and grey seal faeces. Hence, this study consecutively refers to them as seal faecal samples.

The following steps were conducted in a closed acrylic box (see Supplementary Materials) and are applicable for all further investigations on intestinal and faecal samples. The box was equipped with two holes, which formed the only openings within the box, these being necessary for processing the samples. During the whole procedure, the samples were solely processed with glass or metallic instruments. Furthermore, cotton gloves were worn over nitrile ones during all processing steps. 

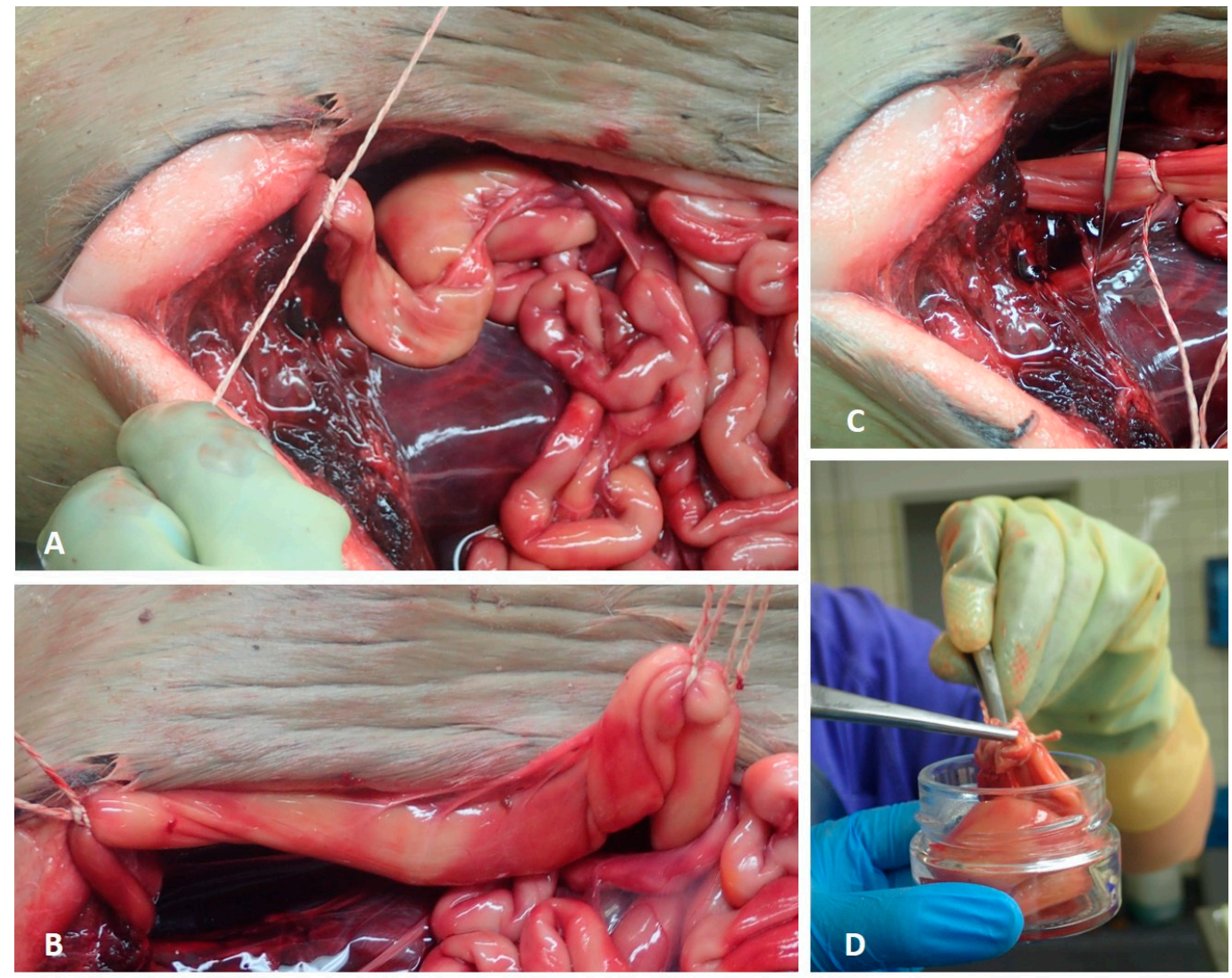

Figure 1. Sampling of intestinal samples: (A) The caudal part of the rectum is tied off; (B) An 8-10 cm section of the rectum is measured in cranial direction and tied off a second time; (C) The intestinal sample is cut with a scalpel and placed with metal tweezers in a glass jar (D).

\subsubsection{Preparation}

After defrosting the samples in the glass jars, the closed intestinal parts were rinsed with MilliQ water (Millipore), measured and opened inside the washing sachets on a glass cutting board to prevent the loss of faeces and potential MP.

For separating the MP from the biogenic matter, the intestine and faeces samples were washed in the above mentioned self-sewn double layer washing sachets in a commercial washing machine (OK., OWM 15012 A1). Each sample was placed in an inner bag (mesh size $300 \mu \mathrm{m}$ ) which was then placed in the outer bag (mesh size $100 \mu \mathrm{m}$ ). The sachets were made of nylon cloth and were sewn together in the acrylic box with a conventional sewing machine (Singer, Tradition TM 2282) using black cotton yarn. Furthermore, each nylon sachet was used only once to prevent a cross-contamination.

\subsubsection{Washing Procedure}

The washing procedure of the samples was based on the protocol established by Bravo Rebolledo et al. [17]. To remove biogenic organic matter, enzyme-based washing powder (Biote ${ }^{\circledR}$, stain removing powder, biological detergent, bleach free; $35 \mathrm{~g}$ ) was added in the prewash cycle. Subsequently, conventional detergent ( 35 g, Gut \& Guenstig Classic, Edeka Zentrale AG \& Co. KG, Hamburg, Germany) was used in the main wash cycle, assisting the cleaning procedure. The samples were washed in a delicate wash cycle without spinning at $60^{\circ} \mathrm{C}$. A delicate wash cycle without spinning was chosen in order to prevent particles from escaping from the sachets and thus not being available for further analysis. For a valid evaluation, all samples were weighed before and after the washing procedure, to quantify the loss of biogenic compounds (e.g., blood, faeces, soft tissue). 
Prior to each wash cycle, an empty wash cycle was run using disinfectant (Impresan, Brauns-Heitmann GmbH \& Co.KG, Warburg, Germany) at $90{ }^{\circ} \mathrm{C}$. This step cleaned the washing machine and additionally reduced the likelihood of cross-contamination.

\subsubsection{Isolation}

After the washing procedure, the washing sachets containing the sample residues were covered in aluminium foil and stored in a half-closed box under a fume hood for drying overnight. The outsides of the sachets were cleaned with MilliQ water prior to opening. The residue was rinsed with a filtered, saturated sodium chloride $(\mathrm{NaCl})$ solution ( $350 \mathrm{~g}$ of table salt dissolved in 11 of MilliQ water) in glass beakers. The solution was left overnight for density separation.

Approximately 20 to $30 \mathrm{~mL}$ of the surface of the supernatant was pipetted onto a cellulose filter (Rotilabo ${ }^{\circledR}$, Typ11A, Ø $55 \mathrm{~mm}$, retention 12-15 $\mu \mathrm{m}$ ) using a Buechner funnel (Rotilabo ${ }^{\circledR}$, porcelain, volume: $70 \mathrm{~mL}$; $\varnothing 5 \mathrm{~mm}$ ) attached to a vacuum pump. The remaining solution and the sediment were decanted onto a second filter. Both surface and bottom sample suspensions were investigated separately in order to avoid an MP underestimation. The filtration steps resulted in a total of four filters for each sample (inner bag: surface water and water from the beaker bottom; outer bag: surface water and water from the beaker bottom).

The filters were stored in glass petri dishes (STERIPLAN ${ }^{\circledR}, \varnothing 60 \mathrm{~mm}$ ) and dried in a heating cabinet for three hours at $50{ }^{\circ} \mathrm{C}$. Until further processing, the closed petri dishes including the sample filter were stored in a closed and dry environment.

\subsubsection{Pre-Trials to Verify the Procedure}

The methodical efficiency was evaluated, focusing on potential losses of particles and secondary contaminations. The use of washing sachets was assessed for potential loss of particles and loss of nylon fibres and thus the recovery rate. To determine the loss of potential MP, polyethylene microbeads (fragment size: 150-800 $\mu \mathrm{m}$ ) were placed in the nylon sachets and processed in the same manner as the intestine and scat samples.

Prior to sample processing, five sachets were solely washed without any detergent and sample (at $60{ }^{\circ} \mathrm{C}$, delicate cycle, no spinning cycle as mentioned above). A Cora ball ${ }^{\circledR}$, which traps loose fibres, was added and showed no attached fibres after the washing procedure.

\subsubsection{Polymer Identification}

For identifying possible MP, the filters were stained with Nile Red diluted in chloroform $(1 \mathrm{mg} / \mathrm{mL}$ in chloroform) after Tamminga et al. [32]. The stained filters remained covered for drying for at least $24 \mathrm{~h}$, before being analysed under a plan fluorescence microscope (Kern OBN- 148 and Zeiss AX10) using a TRITC HC filter set (F36-503, AHF Analysetechnik, Tuebingen, Germany) in accordance with Tamminga et al. [32].

Potential MP particles were photographed (Kern ODC 832 and Canon EOS 80D) under the fluorescence microscope. Subsequently, the photos were visually evaluated, and the suspected MP were measured and counted by using Adobe Photoshop (Version 21.0.3). After visual identification, single particles were isolated with tweezers and pins, and placed on microscopic slides for further identification by $\mu$ Raman spectroscopy (ThermoFisher Scientific Inc., Waltham, MA, USA; DXR2xi Raman Imaging Microscope).

In general, direct comparisons among different studies are hampered due to the varying sample treatment protocols and mesh sizes being used. To address this problem, the present study followed the sample processing conducted by Bravo Rebolledo et al. [17] and focussed on particle sizes $\geq 100 \mu \mathrm{m}$. In this study, the term MP included synthetic fragments and fibres. The classification of fibres was used, if a fragment has an elongated cylindrical shape and a thickness of up to $23 \mu \mathrm{m}$.

All particles larger than $100 \mu \mathrm{m}$ were taken into account for valid results due to the used mesh size $(100 \mu \mathrm{m})$ of the outer washing sachet to avoid an overestimation. Two researchers independently 
investigated the photos taken of particles to identify the potential MP. The following parameters were used for discrimination: fluorescence intensity and appearance of the particle (surface, isolation, completeness, etc.). For additional information, see the Supplementary Materials.

Based on the aforementioned discrimination parameters, we used recursive partitioning to explore decision rules for predicting whether the particle was plastic or not. The decision tree was created in RStudio (Version 1.1.447) with the package "rpart" R package rpart.plot [43] with 1185 characterised particles (biogenic or synthetic). The number of particles resulted fromavailable MP samples including pinnipeds and cetaceans from the North and Baltic Seas, where this study group was involved in. It builds the basis for the used parameters in the decision tree. The original dataset $(n=1185)$ was randomly split into training $(80 \%)$ and test $(20 \%)$ subsets. The training subset was used for model tuning and training and the performance of the final model was compared using the Test subset.

\subsection{Evaluation of the Methodical Efficiency}

In the present study, the entire working space was located in an acrylic box situated under a fume hood to decrease the potential secondary contamination of samples and used items. All equipment and instruments were rinsed several times with MilliQ water prior to usage. The box was washed with MilliQ water and wiped between each step with cotton cloths, which were exchanged regularly.

For monitoring secondary contamination, procedural blanks of the applied chemicals and detergents were used in accordance with Hengstmann et al. [44] and Nuelle et al. [45]. Procedural blanks helped to estimate the number of particles being introduced during the processing; particles on the procedural blank filters were separately quantified, measured and qualified. Contamination of cloths or instruments was deducted after the quantitative analysis as performed in former studies.

To prove the possible contamination of plastic bags, five faecal samples which had been frozen in low-density polyethylene (LDPE) bags since 2012 were used. Nine faecal samples were additionally included in this study. These samples were divided: half of each sample was stored in LDPE-bags, the other half in glass jars for three, six and 12 months. The plastic bags in which the samples are stored were not disinfected or cleaned prior usage. The comparison of the found number of particles in glass jars and plastic samples was performed using a Wilcoxon signed-rank test, due to the relation between the samples and the assumption of a non-normal distribution. To test whether the findings of suspected MP increased over time, the plastic samples taken from different periods were analysed by a non-parametric ANOVA using a Kruskal-Wallis test.

\section{Results}

\subsection{Evaluation of the Methodical Efficiency}

\subsubsection{Procedural Efficiency of Washing Sachets}

The pre-trials showed that a loss of $0.358 \mathrm{~g}(2.99 \%)$ was determined for those sachets, which were closed with a hook-and-loop fastener. Due to this small percentage loss, the usage of nylon cloth was maintained, but the hook-and-loop fastener was discarded and replaced by a seam. For further details, refer to the Supplementary Materials.

By comparing the dry weights of the samples (before and after the washing procedure), the average reduction in biogenic matter in intestinal samples differed between 9.97 and $0.22 \mathrm{~g}$ (mean $=1.57 \mathrm{~g}$ ). In the faecal samples, the average reduction varied between 5.07 and $48.55 \mathrm{~g}$ (mean $=13.33 \mathrm{~g}$ ).

\subsubsection{Efficiency of Contamination Control Measures}

Procedural blanks analysed for the background contamination of the working space showed a share ranging from zero to two particles per sample $(\mathrm{M} \pm \mathrm{SD}=0.9 \pm 0.99)$. Only one fiber larger than $100 \mu \mathrm{m}$ was found on the working environment controls $(n=12)$. One to two fragments were found within the $\mathrm{NaCl}$ blanks $(n=5)$, which also included a potential contamination by the used 
plastic laboratory bottles $(\mathrm{M} \pm \mathrm{SD}=1.4 \pm 0.99)$. Furthermore, five control washing sachets showed a contamination of two to at most eight particles $(\mathrm{M} \pm \mathrm{SD}=4.6 \pm 2.7)$. Therefore, a mean number of seven particles $\geq 100 \mu \mathrm{m}$ (six fragments and one fiber) per sample was considered as contamination. Figure 2 shows the share of suspected MP particles found in the procedural blanks.
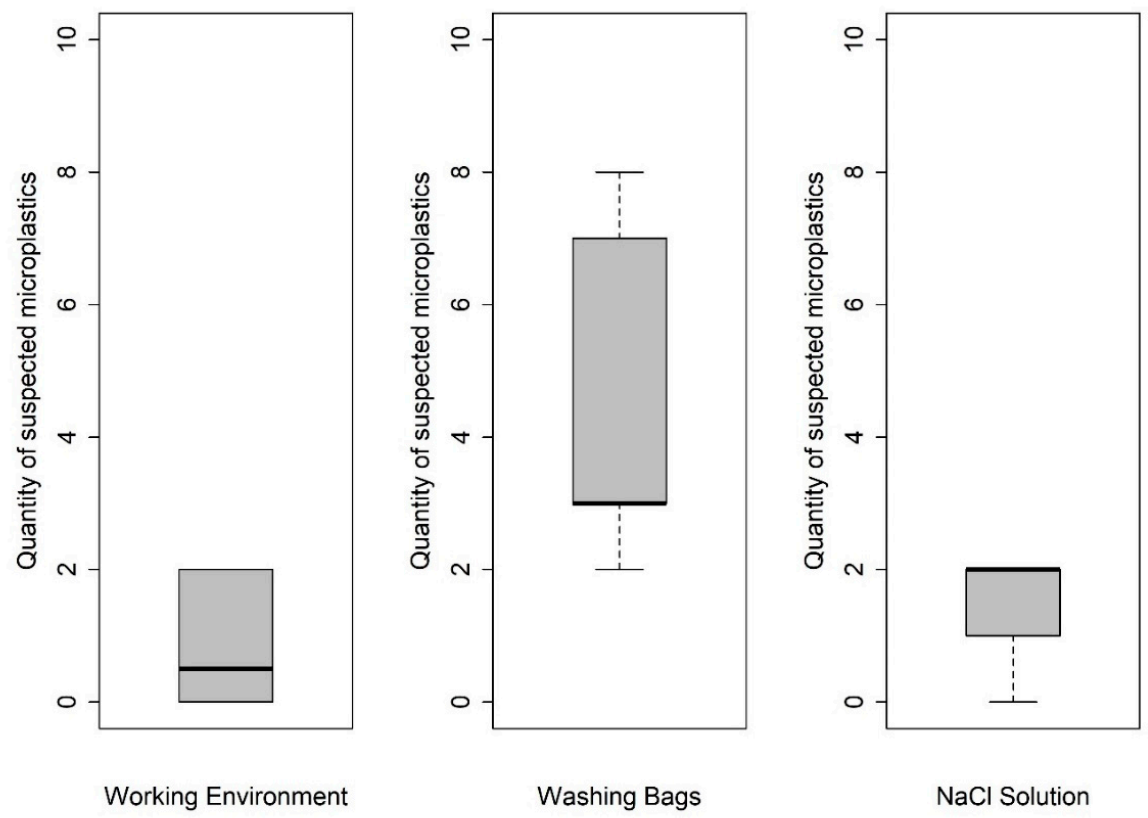

Figure 2. Suspected microplastics (MPs) from procedural blank controls ( $\geq 100 \mu \mathrm{m})$. Working environment: 12 control filter; Washing sachets: Five blank samples; NaCl Solution: Five control samples.

\subsubsection{Comparison of Suitable Storage Methods for Avoiding Contamination}

Each sample archived in a glass jar showed a lower amount of suspected MP compared with those stored in plastic bags (Figure 3). The Wilcoxon test revealed significant differences, showing that plastic stored samples included eight particles $(\geq 100 \mu \mathrm{m})$ more compared with those stored in glass jars (particles $\geq 100 \mu \mathrm{m}: p=0.012$; particles $\leq 100 \mu \mathrm{m}$ : $p=0.0104$ ).

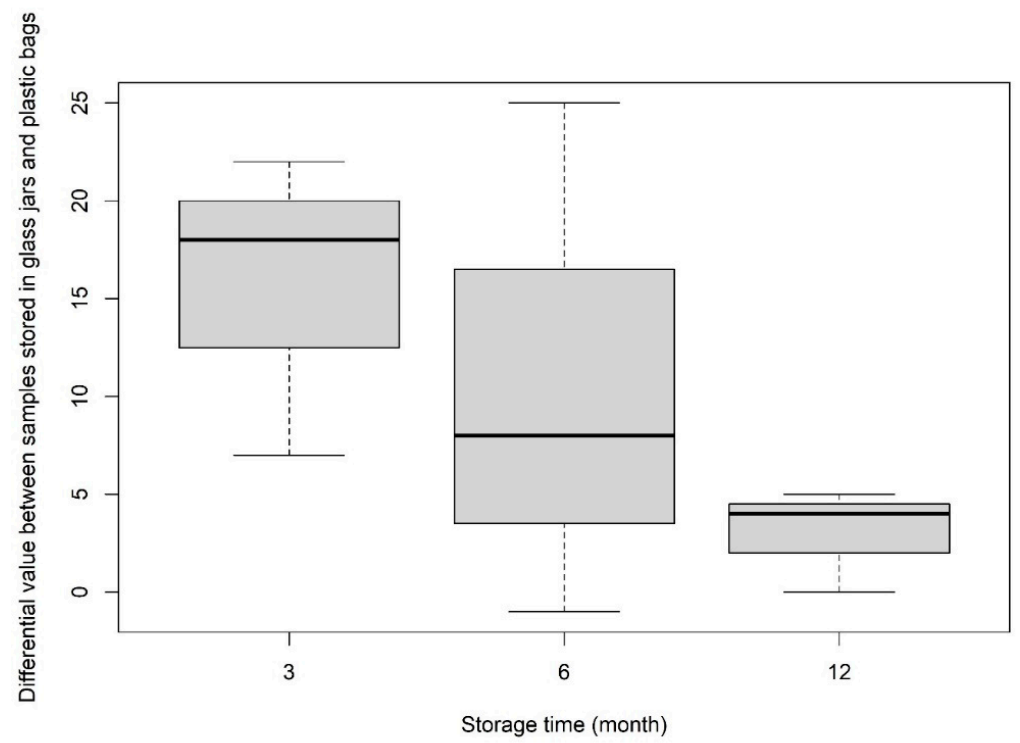

Figure 3. Differential values in the quantity of suspected MPs $(\geq 100 \mu \mathrm{m})$ in samples stored in plastic bags, compared to ones stored in glass jars from different storage times. 
The direct comparison of samples stored for different periods in plastic bags (three, six and 12 months) revealed no significant increase in microplastic particles over time (Figure 3). This was due to a high variability in each period group. However, a comparison with samples, which had been stored in plastic bags for eight years, showed no significant differences to the present samples (Figure 4).

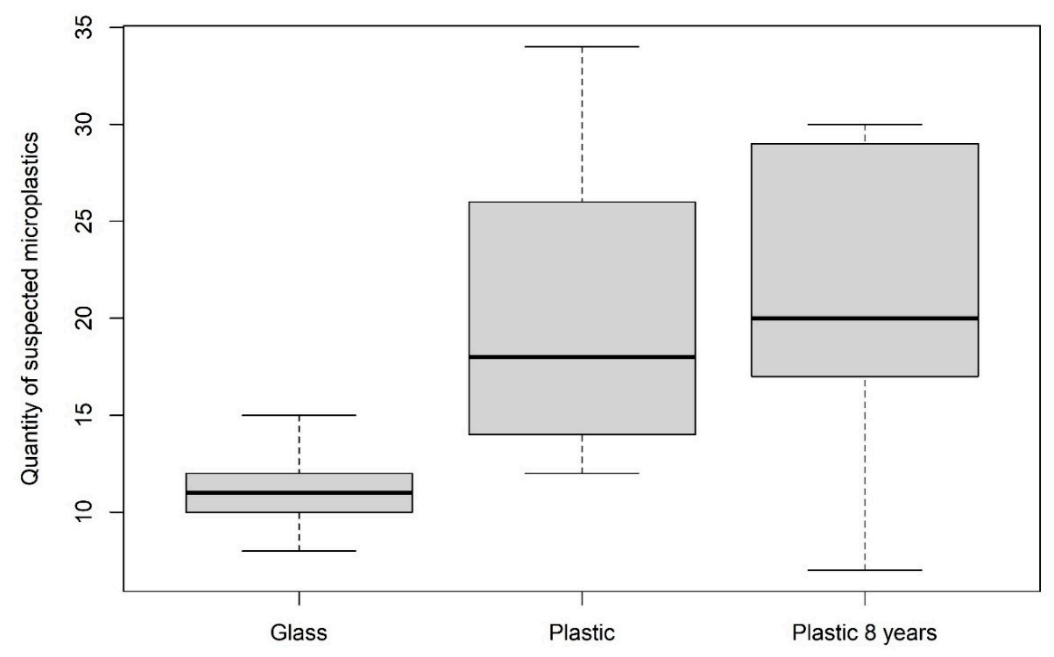

Figure 4. Suspected microplastics in faecal samples stored in glass jars $(n=9)$ and plastic bags $(n=9)$ combined from all storing periods (three, six and 12 months; particles $\geq 100 \mu \mathrm{m}$ ). In addition, five samples of seal faeces, which had been stored in low-density polyethylene (LDPE) bags for eight years, were presented for comparison purposes.

\subsection{Protocol Validation}

The results of the used decision tree (Figure 5) revealed the following parameters to be decisive: (1) If a particle could be associated with a biogenic shape or structure (e.g., crustacean limbs or algae). If yes, it was classified as no MP (No-Plastic). If not, the fluorescent colour of the particle (orange including red and yellow or white) defined the next classification (2). If the fluorescent colour was white, the particle was classified as suspected MP. If the colour was yellow or orange, the next category was the appearance: (3) blurred, melted or defined appearance. If it was defined, the particle was classified as plastic; if not it was identified as No-Plastic. If the fluorescent colour the second category was white, the particle was categorised as plastic. A catalogue of examples and categories is presented in the Supplementary Materials. Potential microplastic particles identified by using this decision tree are than analysed using $\mu$ Raman spectroscopy.

The calculated sensitivity (true positive rate, TPR) of $84 \%$, that measures the proportion of particles that were identified as possible MP and the specificity (true negative rate, TNR) of $69 \%$, which measures the proportion of particles that were identified as being non-plastic, revealed a good performance of the decision tree.

\subsection{Isolation of Potential MP in Intestinal and Faecal Samples}

In total, 653 potential plastic particles were determined in ten intestinal samples of free-ranging harbour and grey seals, and nine seal faecal samples where the described procedure (sample collection, isolation and identification) was used. Due to the used mesh sizes of the washing sachets $(100 \mu \mathrm{m}$ and $300 \mu \mathrm{m}$ ), all particles smaller than $100 \mu \mathrm{m}$ were excluded from the study, resulting in 255 identified suspected MP particles (70 fibres and 185 fragments) in 18 out of a total of 19 samples. The share of fibres ranged from zero to 35 per sample $(\mathrm{M} \pm \mathrm{SD}=6 \pm 7.4)$ when taking all specimens stored in glass jars into consideration $(\geq 100 \mu \mathrm{m})$. The number of fragments $(\geq 100 \mu \mathrm{m})$ in each sample stored in glass jars varied from five to 55 parts $(\mathrm{M} \pm \mathrm{SD}=13.3 \pm 11.3)$. 


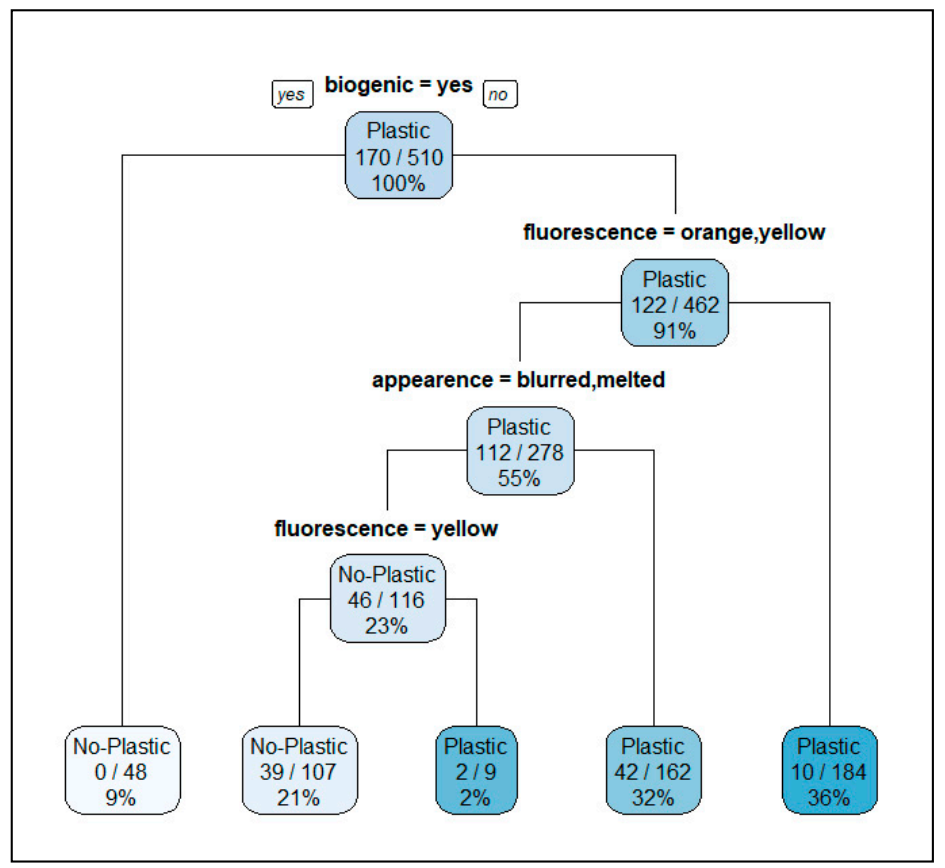

Figure 5. Example of a decision tree of the test set-up of 510 particles showing the decisive parameters.

Some MP findings are shown in Figure 6. For a total of 31 suspected plastic particles, the polymer composition was verified via $\mu$ Raman spectroscopy. 28 particles $(90 \%)$ of these 31 particles were identified as plastic polymer. The following polymers were determined: Polyethylene (PE, $n=14)$, polyethylene terephthalate (PET, $n=5$ ), ethylene-vinyl acetate (EVA, $n=6$ ), polyamide (PA, $n=1$ ) and polypropylene (PP, $n=1$ ). Those particles were collected randomly from all 19 named samples, thus $11 \%$ of the whole quantity of suspected MPs were analysed.
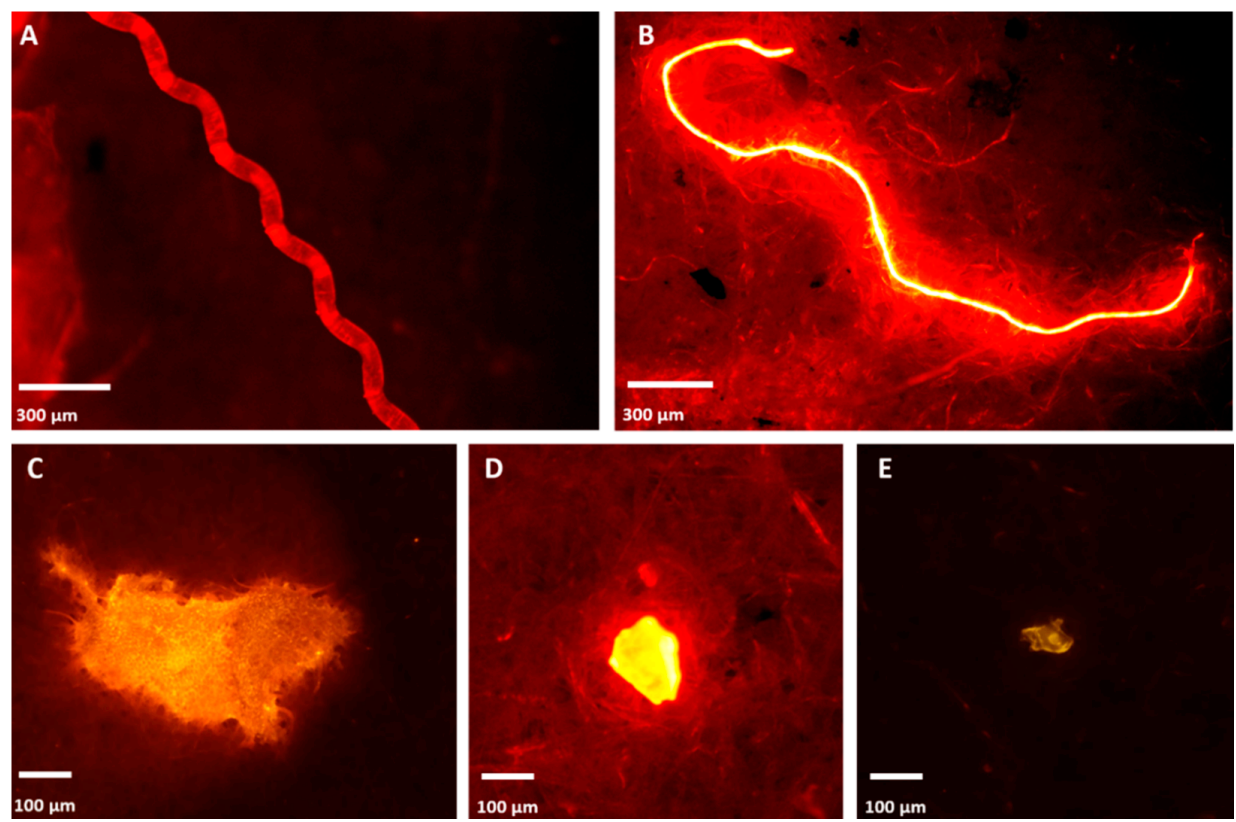

Figure 6. Identified microplastic particles from intestinal samples stained with Nile red photographed under a fluorescence microscope using a TRITC filter: (A) A nylon fibre of the used nylon cloth; (B) a polyethylene terephthalate (PET)-fibre found in a grey seal; (C) an ethylene-vinyl acetate (EVA) particle found in a harbour seal; (D) a polypropylene (PP) particle found in a grey seal; (E) a polyethylene (PE) particle found in a harbour seal. 
Figure 7 shows the higher quantity of particles found in intestinal samples of grey and harbour seals compared with the collected faecal samples where the species is unknown. It is significant that the quantity of suspected MP exceeded the maximal assumed secondary contamination of seven particles per sample (see dotted line in Figure 7).

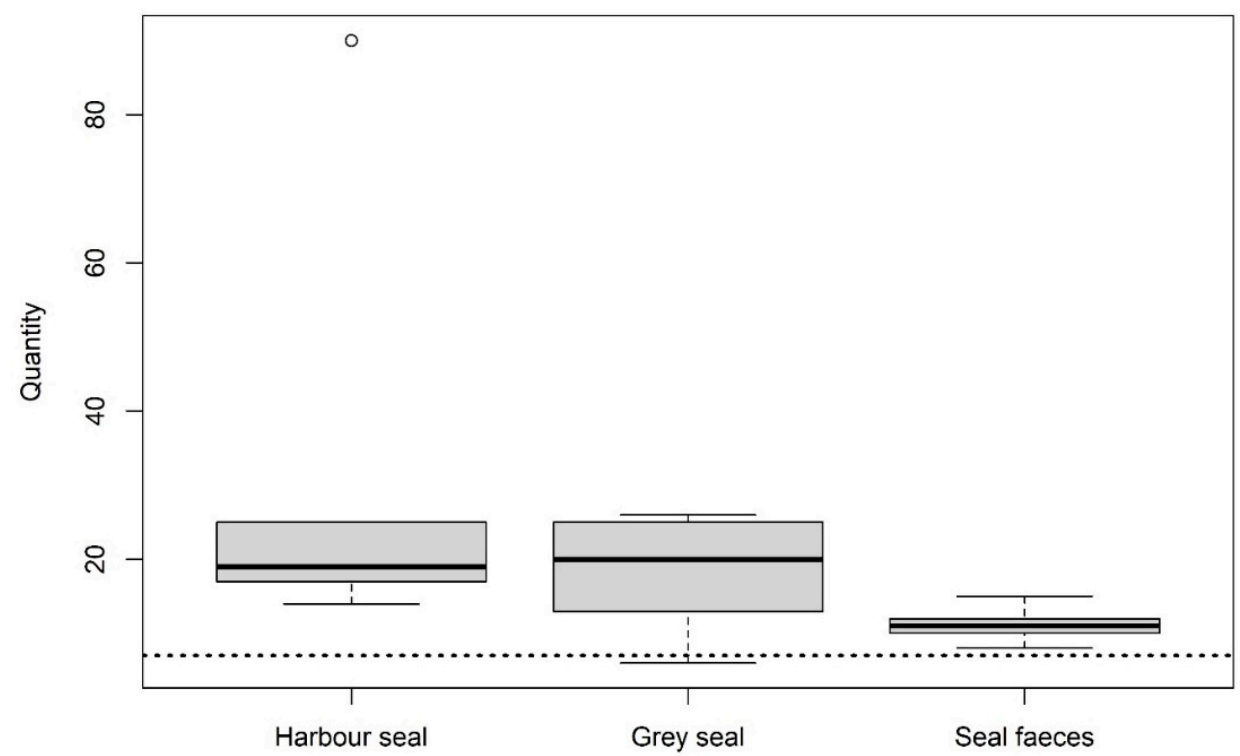

Figure 7. Suspected microplastics in intestinal samples of harbour $(n=5)$ and grey seals $(n=5)$, in comparison to faecal samples from seals collected on the sandbank (Lorenzenplate, North Sea) $(n=9$, no determined species per sample: faeces originated from either a grey or a harbour seal). All samples were stored in glass jars. The dotted line shows the maximal presumption of secondary contamination of seven particles per sample.

\section{Discussion}

An initial and essential step for studying the effects of MP particles in GITs of marine mammals is the detection and evaluation of their current presence and distribution. Apart from assessing the presence of microplastics in marine mammals, the main focus of this study was to improve the avoidance of secondary contamination during sample handling. This problematic nature of secondary contamination, which was also shown in previous studies $[17,26,29,44,46]$, needs to be focused on to achieve genuine results. The presented protocol combines established protocols for isolating MP from biota samples $[17,29]$ with new approaches for specifically avoiding secondary contamination.

The first step for avoiding contamination was to store the samples in glass jars, since they are prone to contamination when stored in conventional plastic bags. The present study presented evidence of this aforementioned fact. The results of the direct comparison between archived samples in plastic bags and in glass jars showed that a contamination by plastic bags is likely. The number of plastic particles did not significantly increase over time, but the basis of contamination from external sources seems to be higher when archiving samples in plastic bags instead of storing them in glass jars. It has to be taken into account that the used samples already show a basic microplastic contamination. This differs from sample to sample, resulting in the fact that the plastic burden of the samples also varies between the time periods. A conceivable parameter besides the polymer structure of plastic bags is the cleaning aspect. Glass jars were cleaned and disinfected prior to usage; plastic bags were used in their original state. Based on the results of this study, it is recommended to use glass jars instead of plastic bags or containers.

A closed working environment was created to improve the measures undertaken in previous studies to prevent secondary contamination. The procedural blanks analysed for the background contamination of the working space showed a very low number of particles ( $0-2$ per sample). 
Furthermore, the share of fibres was significantly lower in this study compared to similar approaches in marine mammals $[20,21,47,48]$ or other marine species $[33,49,50]$. Additionally, it has been previously highlighted that fibres in particular are an indicator of secondary contamination, originating from the laboratory clothing and working environment $[25,29,44-46,51]$. Therefore, the acrylic box safeguarded the samples from direct contact with the laboratory environment and personnel.

The presented study revealed that closed sealing, like the washing sachet, reduces the loss of particles. To minimise the risk of losing particles as well as reducing the contamination of the samples, it is advisable to place the samples into a nylon cloth, which is then sewn together. Pre-trials revealed the application of hook-and-loop fasteners to be unsatisfactory (see Supplementary Materials); similar results are noted for rubber bands [52].

The usage of nylon cloths was inevitable due to the favourable mesh sizes and the fact that no solid material can be used in the washing machine, although polyamide (nylon) is one of the most abundant polymers [53,54]. Indeed, fibres of the nylon washing sachets can be easily identified showing a distinct fibre pattern and were therefore not included in our study. Thus, there was no need to exclude polyamides from this study if these polymers were found. To validate this assumption, a found fibre showing a distinct structure and fluorescence intensity compared with the fibres of the used nylon cloths was identified as polyamide (nylon) by $\mu$ Raman spectroscopy. Therefore, the polymer identification via $\mu$ Raman spectroscopy was used to manifest the presence of microplastics and is an already established and reliable application in microplastic analysis [37,55-57]. Thus, the benefits of this applied cleaning procedure (1. time and cost effective, 2 . valuable results) outweigh the disadvantages of the used nylon cloths. The usage of a conventional washing machine and detergent was demonstrated as a successful application to speed up the purification procedure resulting in clean residues. Removing biogenic substances with the help of the washing procedure preserves the original particles, and it is less time- (approx. $90 \mathrm{~min}$ ) and budget-consuming compared with the application of enzymatic or chemical solutions for the digestion of biogenic material. Thus, the reduction of biogenic compounds (e.g., faeces, blood, and soft remains of prey species) was effective to decrease the sample to the remaining hard parts (e.g., sand grains, fish bones and lenses, beaks, and microplastics), as also seen by the compared dry weights. These results are also shown by the comparison of dry weights before and after the washing procedure. In the intestinal samples, the intestinal tissue and the hard parts remained. A mean difference of $1.75 \mathrm{~g}$ was determined. In comparison to the faecal samples where a mean difference of $13.33 \mathrm{~g}$ was ascertained. The weights were mostly dependent on the quantity of hard parts (e.g., sand grains, fish otoliths, and lenses, bones or squid beaks) within the respective sample. Furthermore, the weight of pure faeces was higher in the sandbank faecal samples (mean $=19.52 \mathrm{~g}$ ) compared to faeces included in the intestinal tissue (mean $=15.06 \mathrm{~g}$ ). Firstly, these differences can be explained by the intestinal physiology of phocid species, with a short length of the large intestine where the chymus is dehydrated and stored as faeces until excretion [58,59]. Secondly, passage times of marine mammals have to be taken into account if an assessment of the microplastic burden in marine mammals is required [60]. The passage times of harbour seals and grey seals were estimated to last for 6.5 to $30 \mathrm{~h}[61,62]$. Thus, the sandbank samples may include the faeces of a full egestion of the rectum. In contrast, the intestinal samples represent only a part of the actual excretion, which is here further analysed. Furthermore, a reduction in size and loss of microplastics is conceivable as is confirmed for otoliths [63]. Combining collected faecal and intestinal samples is advisable for further investigations as this will display the burden of microplastics in an extended way.

Besides the method, there are more side parameters which have to be considered while collecting samples from wild ranging animals. This study only investigated in a part of the intestinal system instead of examining the whole GIT or the stomach as performed in recent studies $[20,47,64]$. This step was chosen to enable a potential contamination-free sample although a complete examination of the residual GIT and the carcass can be conducted. The reason for this is the usage of one organ for only one assessment is applicable in the fewest of cases during necropsies. Another benefit of this strategy 
is the unhindered necropsy of the whole individual, which enables an entire overview of the health status and possibly provides more background information.

The number of positive samples (suspected MP $\geq 100 \mu \mathrm{m}$, in glass jars) is higher than in similar studies of faecal samples of seal species from the northern and southern Pacific Ocean [21,65] despite it is being conformable with studies investigating marine mammals of the north-eastern North Atlantic region $[20,47,66]$. As a consequence of the results of the used statistical applications (precision of $94 \%$ and sensitivity of $84 \%$ ), in combination with the $90 \%$ chance of a correct classification as MP, this study is assumed to be a valuable approach in MP monitoring in marine mammals.

The establishment of a decision tree helps to categorize different variables, which are helpful for untrained researchers to gain results that are comparable between research groups. This is essential to compare the burden in different marine environments and biota. Furthermore, the decision tree helps to narrow down suspected microplastic particles out of a bunch of a variety of particles in a sample, which are then used for further analysis. This is cost- and time-effective and a useful tool for encouraging decision makers to support necessary monitoring programmes.

In addition, the applied methods comprise a combination of interdisciplinary analyses: identifying microplastics and their consumed prey (diet analysis of hard parts). This is based on the conciliatory washing procedure; the retained hard parts can be used for prey species identification [52,67]. Since it is proven that microplastics are transported across the food web $[14,16,68]$, it is assumed that in particular the contained contaminants accumulate due to absorption and leaching [69] in top predator species as itis already evidenced, for example, for organochlorides $[70,71]$. This allows new insights into the correlation between microplastic occurrence in marine top predator species and their prey, which serve as a vector.

\section{Conclusions}

The sample protocol applied within this study is applicable for isolating and identifying microplastics from samples of gastrointestinal tracts of marine mammals and is comparable with other approaches like diet analysis. Low numbers of detected fibres led to the conclusion that secondary contamination is low. This seems most likely to be an effect of using a closed environment, the acrylic box and the usage of glass jars as storage container. Furthermore, the used isolation procedure is less cost-intensive, more gentle and faster in comparison to an enzyme or chemical digestion. However, every working environment and samples of different species and different sizes pose different challenges for microplastic analysis.

It can be assumed that the current approach provides reliable results, reflecting the actual microplastic burden in the analysed species. Thus, this study presents a possible application for microplastic monitoring in marine mammal samples, which has to be extended to a higher number of samples to achieve convincing findings in different species and water bodies. Nevertheless, this method is also transferable to other mammalian species.

Supplementary Materials: The following are available online at http://www.mdpi.com/2071-1050/12/24/10424/s1.

Author Contributions: Conceptualization, B.U. and C.P.; Methodology, B.U. and C.P.; Investigation: C.P.; Formal analysis and Validation: J.G.S. and C.P.; Supervision: U.S. and E.K.F.; Resources: E.K.F. and U.S.; Writing-original draft: C.P.; Writing—review and editing: B.U., E.K.F., J.G.S., U.S. and C.P. All authors have read and agreed to the published version of the manuscript.

Funding: The stranding network and the health monitoring is funded by the Schleswig-Holstein Agency for Coastal Defence, National Park and Marine Conservation, Germany. The pathological investigations of the marine mammals are partly funded by the Ministry of Energy, Agriculture, Environment, Nature and Digitalization of Schleswig-Holstein, Germany. The Federal Environment Agency (UBA) partly funded the analysis of a number of samples within the project "Assessment and implementation for long-term monitoring of pollution of diverse marine compartments and biota with marine litter" (FKZ 3717252250). This publication was supported by the German Research Funding Organisation (Deutsche Forschungsgemeinschaft) and the University of Veterinary Medicine Hannover, Foundation (Germany), within the funding programme Open Access Publishing. 
Acknowledgments: We would like to thank all seal rangers in Schleswig-Holstein (SH), Germany for reporting and collecting carcasses as well as our colleagues in the ITAW necropsy team for collecting and dissecting carcasses continuously throughout the year. Special thanks go to E. Ludes-Wehrmeister and S. Gross for advising us regarding tissue sampling and storing. We would like to thank the "Microplastic Research at CEN-MRC" working group at the University of Hamburg (Germany), for their assistance and hospitality. Special thanks in particular go to M. Tamminga for sharing his expertise.

Conflicts of Interest: The authors declare no conflict of interest. The funders had no role in the design of the study; in the collection, analyses, or interpretation of data; in the writing of the manuscript, or in the decision to publish the results.

\section{References}

1. Galgani, F.; Hanke, G.; Maes, T. Global distribution, composition and abundance of marine litter. In Marine Anthropogenic Litter; Bergmann, M., Gutow, L., Klages, M., Eds.; Springer: Cham, Switzerland, 2015; pp. $29-56$. [CrossRef]

2. Thompson, R.C.; Olsen, Y.; Mitchell, R.P.; Davis, A.; Rowland, S.J.; John, A.W.G.; McGonigle, D.; Russell, A.E. Lost at Sea: Where is all the plastic? Science 2004, 304, 838. [CrossRef] [PubMed]

3. Thiel, M.; Hinojosa, I.A.; Miranda, L.; Pantoja, J.F.; Rivadeneira, M.M.; Vásquez, N. Anthropogenic marine debris in the coastal environment: A multi-year comparison between coastal waters and local shores. Mar. Pollut. Bull. 2013, 71, 307-316. [CrossRef] [PubMed]

4. Ryan, P.G.; Moore, C.J.; van Franeker, J.A.; Moloney, C.L. Monitoring the abundance of plastic debris in the marine environment. Philos. Trans. R. Soc. B Biol. Sci. 2009, 364, 1999-2012. [CrossRef] [PubMed]

5. Arthur, C.; Baker, J.; Bamford, H. NOAA technical memorandum NOS-OR\&R-30. In Proceedings of the International Research Workshop on the Occurrence, Effects, and Fate of Microplastic Marine Debris, Tacoma, WA, USA, 9-11 September 2008; Available online: https://repository.library.noaa.gov/view/noaa/2509 (accessed on 13 December 2020).

6. Gregory, M.R.; Andrady, A.L. Plastics in the marine environment. In Plastics and the Environment; Andrady, A.L., Ed.; John Wiley \& Sons, Inc.: Hoboken, NJ, USA, 2003; pp. 389-390.

7. Andrady, A.L. Persistence of plastic litter in the oceans. In Marine anthropogenic Litter; Bergmann, M., Gutow, L., Klages, M., Eds.; Springer: Cham, Switzerland, 2015; pp. 57-72. [CrossRef]

8. Browne, M.A.; Galloway, T.; Thompson, R. Microplastic-an emerging contaminant of potential concern? Integr. Environ. Assess. Manag. 2007, 3, 559-561. [CrossRef]

9. Cole, M.; Lindeque, P.; Halsband, C.; Galloway, T.S. Microplastics as contaminants in the marine environment: A review. Mar. Pollut. Bull. 2011, 62, 2588-2597. [CrossRef]

10. Carpenter, E.J.; Anderson, S.J.; Harvey, G.R.; Miklas, H.P.; Peck, B.B. Polystyrene spherules in coastal waters. Science 1972, 178, 749-750. [CrossRef]

11. Morris, A.W.; Hamilton, E.I. Polystyrene spherules in the Bristol channel. Mar. Pollut. Bull. 1974, 5, $26-27$. [CrossRef]

12. Hermsen, E.; Mintenig, S.M.; Besseling, E.; Koelmans, A.A. Quality criteria for the analysis of microplastic in biota samples: A critical review. Environ. Sci. Technol. 2018, 52, 10230-10240. [CrossRef]

13. Zhang, S.; Wang, J.; Liu, X.; Qu, F.; Wang, X.; Wang, X.; Li, Y.; Sun, Y. Microplastics in the environment: A review of analytical methods, distribution, and biological effects. TrAC Trends Anal. Chem. 2019, 111, 62-72. [CrossRef]

14. Farrell, P.; Nelson, K. Trophic level transfer of microplastic: Mytilus Edulis (L.) to Carcinus Maenas (L.). Environ. Pollut. 2013, 177, 1-3. [CrossRef]

15. Rummel, C.D.; Löder, M.G.J.; Fricke, N.F.; Lang, T.; Griebeler, E.-M.; Janke, M.; Gerdts, G. Plastic ingestion by pelagic and demersal fish from the North sea and Baltic sea. Mar. Pollut. Bull. 2016, 102, 134-141. [CrossRef] [PubMed]

16. Setälä, O.; Fleming-Lehtinen, V.; Lehtiniemi, M. Ingestion and transfer of microplastics in the planktonic food web. Environ. Pollut. 2014, 185, 77-83. [CrossRef] [PubMed]

17. Rebolledo, B.E.L.; Van Franeker, J.A.; Jansen, O.E.; Brasseur, S.M.J.M. Plastic ingestion by harbour seals (Phoca Vitulina) in The Netherlands. Mar. Pollut. Bull. 2013, 67, 200-202. [CrossRef] [PubMed] 
18. Unger, B.; Rebolledo, E.L.B.; Deaville, R.; Gröne, A.; IJsseldijk, L.L.; Leopold, M.F.; Siebert, U.; Spitz, J.; Wohlsein, P.; Herr, H. Large amounts of marine debris found in sperm whales stranded along the North sea coast in early 2016. Mar. Pollut. Bull. 2016, 112, 134-141. [CrossRef] [PubMed]

19. Unger, B.; Herr, H.; Benke, H.; Böhmert, M.; Burkhardt-Holm, P.; Dähne, M.; Hillmann, M.; Wolff-Schmidt, K.; Wohlsein, P.; Siebert, U. Marine debris in harbour porpoises and seals from German waters. Mar. Environ. Res. 2017, 130, 77-84. [CrossRef] [PubMed]

20. Nelms, S.E.; Barnett, J.; Brownlow, A.; Davison, N.J.; Deaville, R.; Galloway, T.S.; Lindeque, P.K.; Santillo, D.; Godley, B.J. Microplastics in marine mammals stranded around the British coast: Ubiquitous but transitory? Sci. Rep. 2019, 9, 1075. [CrossRef]

21. Donohue, M.J.; Masura, J.; Gelatt, T.; Ream, R.; Baker, J.D.; Faulhaber, K.; Lerner, D.T. Evaluating exposure of northern fur seals, callorhinus ursinus, to microplastic pollution through fecal analysis. Mar. Pollut. Bull. 2019, 138, 213-221. [CrossRef]

22. Löder, M.G.J.; Gerdts, G. Methodology used for the detection and identification of microplastics-A critical appraisal. In Marine Anthropogenic Litter; Bergmann, M., Gutow, L., Klages, M., Eds.; Springer International Publishing: Berlin/Heidelberg, Germany, 2015; pp. 201-227. [CrossRef]

23. Cole, M.; Webb, H.; Lindeque, P.K.; Fileman, E.S.; Halsband, C.; Galloway, T.S. Isolation of microplastics in biota-rich seawater samples and marine organisms. Sci. Rep. 2014, 4, 4528. [CrossRef]

24. Woodall, L.C.; Sanchez-Vidal, A.; Canals, M.; Paterson, G.L.J.; Coppock, R.; Sleight, V.; Calafat, A.; Rogers, A.D.; Narayanaswamy, B.E.; Thompson, R.C. The deep sea is a major sink for microplastic debris. R. Soc. Open Sci. 2014, 1, 140317. [CrossRef]

25. Hidalgo-Ruz, V.; Gutow, L.; Thompson, R.C.; Thiel, M. Microplastics in the marine environment: A review of the methods used for identification and quantification. Environ. Sci. Technol. 2012, 46, 3060-3075. [CrossRef]

26. Foekema, E.M.; De Gruijter, C.; Mergia, M.T.; van Franeker, J.A.; Murk, A.J.; Koelmans, A.A. Plastic in North sea fish. Environ. Sci. Technol. 2013, 47, 8818-8824. [CrossRef] [PubMed]

27. Roux, C.; Huttunen, J.; Rampling, K.; Robertson, J. Factors affecting the potential for fibre contamination in purpose-designed forensic search rooms. Sci. Justice 2001, 41, 135-144. [CrossRef]

28. Vandermeersch, G.; Van Cauwenberghe, L.; Janssen, C.R.; Marques, A.; Granby, K.; Fait, G.; Kotterman, M.J.J.; Diogène, J.; Bekaert, K.; Robbens, J.; et al. A critical view on microplastic quantification in aquatic organisms. Environ. Res. 2015, 143, 46-55. [CrossRef] [PubMed]

29. Lusher, A.; Hernandez-Milian, G. Microplastic extraction from marine vertebrate digestive tracts, regurgitates and scats: A protocol for researchers from all experience levels. Bio Protoc. 2018, 8. [CrossRef]

30. Catarino, A.I.; Thompson, R.; Sanderson, W.; Henry, T.B. Development and optimization of a standard method for extraction of microplastics in mussels by enzyme digestion of soft tissues. Environ. Toxicol. Chem. 2017, 36, 947-951. [CrossRef]

31. Claessens, M.; Van Cauwenberghe, L.; Vandegehuchte, M.B.; Janssen, C.R. New Techniques for the detection of microplastics in sediments and field collected organisms. Mar. Pollut. Bull. 2013, 70, 227-233. [CrossRef]

32. Tamminga, M.; Hengstmann, E.; Fischer, E.K. Nile red staining as a subsidiary method for microplastic quantification: A comparison of three solvents and factors influencing application reliability. SDRP J. Earth Sci. Environ. Stud. 2017, 2. [CrossRef]

33. Fischer, E. Distribution of Microplastics in Marine Species of the Wadden Sea along the Coastline of Schleswig-Holstein, Germany; Hamburg University: Hamburg, Germany, 2019.

34. Mintenig, S.M.; Int-Veen, I.; Löder, M.G.J.; Primpke, S.; Gerdts, G. Identification of microplastic in effluents of waste water treatment plants using focal plane array-based micro-fourier-transform infrared imaging. Water Res. 2017, 108, 365-372. [CrossRef]

35. Primpke, S.; Lorenz, C.; Rascher-Friesenhausen, R.; Gerdts, G. An automated approach for microplastics analysis using focal plane array (FPA) FTIR microscopy and image analysis. Anal. Methods 2017, 9, 1499-1511. [CrossRef]

36. Jung, M.R.; Horgen, F.D.; Orski, S.V.; Rodriguez, V.; Beers, K.L.; Balazs, G.H.; Jones, T.T.; Work, T.M.; Brignac, K.C.; Royer, S.J.; et al. Validation of ATR FT-IR to identify polymers of plastic marine debris, including those ingested by marine organisms. Mar. Pollut. Bull. 2018, 127, 704-716. [CrossRef]

37. Lenz, R.; Enders, K.; Stedmon, C.A.; Mackenzie, D.M.A.; Nielsen, T.G. A critical assessment of visual identification of marine microplastic using raman spectroscopy for analysis improvement. Mar. Pollut. Bull. 2015, 100, 82-91. [CrossRef] [PubMed] 
38. Karbalaei, S.; Golieskardi, A.; Hamzah, H.B.; Abdulwahid, S.; Hanachi, P.; Walker, T.R.; Karami, A. abundance and characteristics of microplastics in commercial marine fish from Malaysia. Mar. Pollut. Bull. 2019, 148, 5-15. [CrossRef] [PubMed]

39. Shim, W.J.; Hong, S.H.; Eo, S.E. Identification methods in microplastic analysis: A review. Anal. Methods 2017, 9, 1384-1391. [CrossRef]

40. Siebert, U.; Wünschmann, A.; Weiss, R.; Frank, H.; Benke, H.; Frese, K. Post-mortem findings in Harbour porpoises (Phocoena Phocoena) from the German North and Baltic Seas. J. Comp. Pathol. 2001, 124, 102-114. [CrossRef] [PubMed]

41. Siebert, U.; Wohlsein, P.; Lehnert, K.; Baumgärtner, W. Pathological findings in harbour seals (Phoca Vitulina): 1996-2005. J. Comp. Pathol. 2007, 137, 47-58. [CrossRef] [PubMed]

42. Hasselmeier, I.; Fonfara, S.; Driver, J.; Siebert, U. Differential hematology profiles of free-ranging, rehabilitated, and captive harbor seals (Phoca Vitulina) of the German North Sea. Aquat. Mamm. 2008, 34, 149-156. [CrossRef]

43. Tamminga, M.; Stoewer, S.-C.; Fischer, E.K. On the representativeness of pump water samples versus manta sampling in microplastic analysis. Environ Pollut. 2019, 254. [CrossRef]

44. Therneau, T.; Atkinson, B.; Ripley, B. Rpart: Recursive Partitioning and Regression Trees. R Packageversion 4.1-15. 2019. Available online: https://cran.r-project.org/package=rpart (accessed on 18 August 2020).

45. Hengstmann, E.; Tamminga, M.; vom Bruch, C.; Fischer, E.K. Microplastic in beach sediments of the isle of rügen (Baltic Sea)—Implementing a novel glass elutriation column. Mar. Pollut. Bull. 2018, 126, 263-274. [CrossRef]

46. Nuelle, M.-T.; Dekiff, J.H.; Remy, D.; Fries, E. A new analytical approach for monitoring microplastics in marine sediments. Environ. Pollut. 2014, 184, 161-169. [CrossRef]

47. Torre, M.; Digka, N.; Anastasopoulou, A.; Tsangaris, C.; Mytilineou, C. Anthropogenic microfibres pollution in marine biota. A new and simple methodology to minimize airborne contamination. Mar. Pollut. Bull. 2016, 113, 55-61. [CrossRef]

48. Lusher, A.L.; Hernandez-Milian, G.; Berrow, S.; Rogan, E.; O'Conner, I. Incidence of marine debris in cetaceans stranded and bycaught in Ireland: Recent findings and a review of histological knowledge. Environ. Pollut. 2018, 467-476. [CrossRef] [PubMed]

49. Nelms, S.E.; Galloway, T.S.; Godley, B.J.; Jarvis, D.S.; Lindeque, P.K. Investigating microplastic trophic transfer in marine top predators. Environ. Pollut. 2018, 238, 999-1007. [CrossRef] [PubMed]

50. Lusher, A.L.; McHugh, M.; Thompson, R.C. Occurrence of microplastics in the gastrointestinal tract of pelagic and demersal fish from the English channel. Mar. Pollut. Bull. 2013, 67, 94-99. [CrossRef] [PubMed]

51. Steer, M.; Cole, M.; Thompson, R.C.; Lindeque, P.K. Microplastic ingestion in fish larvae in the western English channel. Environ. Pollut. 2017, 226, 250-259. [CrossRef] [PubMed]

52. Lusher, A.L.; Welden, N.A.; Sobral, P.; Cole, M. Sampling, isolating and identifying microplastics ingested by fish and invertebrates. Anal. Methods 2017, 9, 1346-1360. [CrossRef]

53. Orr, A.J.; Laake, J.L.; Dhruv, M.I.; Banks, A.S.; DeLong, R.L.; Huber, H.R. Comparison of processing pinniped scat samples using a washing machine and nested sieves. Wildl. Soc. Bull. 2003, 31, 253-257.

54. Ter Halle, A.; Ladirat, L.; Martignac, M.; Mingotaud, A.F.; Boyron, O.; Perez, E. To what extent are microplastics from the open ocean weathered? Environ. Pollut. 2017, 227, 167-174. [CrossRef]

55. Andrady, A.L. Microplastics in the marine environment. Mar. Pollut. Bull. 2011, 62, 1596-1605. [CrossRef]

56. Lang, P.L.; Katon, J.E.; O'Keefe, J.F.; Schiering, D.W. The identification of fibers by infrared and raman microspectroscopy. Microchem. J. 1986, 34, 319-331. [CrossRef]

57. Cabernard, L.; Roscher, L.; Lorenz, C.; Gerdts, G.; Primpke, S. Comparison of raman and fourier transform infrared spectroscopy for the quantification of microplastics in the aquatic environment. Environ. Sci. Technol. 2018, 52, 13279-13288. [CrossRef]

58. Helm, R.C. Intestinal length of three California pinniped species. J. Zool. 1983, 199, 297-304. [CrossRef]

59. Pabst, D.A.; Rommel, S.A.; Mclellan, W.A. The functional morphology of marine mammals. In Biology of Marine Mammals; Reynolds, J.E., Rommel, S.A., Eds.; Smithsonian Institution Press: Washington, DC, USA, 1999; pp. 15-72.

60. Panti, C.; Baini, M.; Lusher, A.; Hernandez-Milan, G.; Bravo Rebolledo, E.L.; Unger, B.; Syberg, K.; Simmonds, M.P.; Fossi, M.C. Marine litter: One of the major threats for marine mammals. Outcomes from the European cetacean society workshop. Environ. Pollut. 2019, 247, 72-79. [CrossRef] [PubMed] 
61. Harvey, J.T. Assessment of errors associated with harbour seal (Phoca Vitulina) faecal sampling. J. Zool. 1989, 219, 101-111. [CrossRef]

62. Prime, J.H.; Hammond, P.S. Quantitative assessment of gray seal diet from fecal analysis. In Approaches in Marine Mammal Energetics; The Society for Marine Mammalogy Special Publication: Yarmouth Port, MA, USA, 1987; pp. 165-188.

63. Prime, J.H.; Hammond, P.S. The diet of grey seals from the south-western north sea assessed from analyses of hard parts found in faeces. J. Appl. Ecol. 1990, 27, 435-447. [CrossRef]

64. Lusher, A.L.; Hernandez-Milian, G.; O'Brien, J.; Berrow, S.; O'Connor, I.; Officer, R. Microplastic and macroplastic ingestion by a deep diving, oceanic cetacean: The true's beaked whale mesoplodon mirus. Environ. Pollut. 2015, 199, 185-191. [CrossRef]

65. Perez-Venegas, D.J.; Seguel, M.; Pavés, H.; Pulgar, J.; Urbina, M.; Ahrendt, C.; Galbán-Malagón, C. First detection of plastic microfibers in a wild population of South American fur seals (Arctocephalus Australis) in the Chilean northern Patagonia. Mar. Pollut. Bull. 2018, 136, 50-54. [CrossRef]

66. Hernandez-Milian, G.; Lusher, A.; MacGabban, S.; Rogan, E. Microplastics in grey seal (Halichoerus Grypus) intestines: Are they associated with parasite aggregations? Mar. Pollut. Bull. 2019, 146, 349-354. [CrossRef]

67. Robinson, H.; Thayer, J.; Sydeman, W.J.; Weise, M. Changes in California sea lion diet during a period of substantial climate variability. Mar. Biol. 2018, 165, 169. [CrossRef]

68. Ory, N.C.; Gallardo, C.; Lenz, M.; Thiel, M. Capture, swallowing, and egestion of microplastics by a planktivorous juvenile fish. Environ. Pollut. 2018, 240, 566-573. [CrossRef]

69. Rani, M.; Shim, W.J.; Han, G.M.; Jang, M.; Al-Odaini, N.A.; Song, Y.K.; Hong, S.H. Qualitative analysis of additives in plastic marine debris and its new products. Arch. Environ. Contam. Toxicol. 2015, 69, 352-366. [CrossRef]

70. Siebert, U.; Heidmann, A.; Friedhoff, N.; Kruse, H.; Rigét, F.; Adler, S.; Maser, E. Organochlorine burdens in harbour seals from the German Wadden Sea collected during two phocine distemper epizootics and ringed seals from west Greenland waters. J. Environ. Anal. Toxicol. 2012, 2, 126. [CrossRef]

71. Ross, P.; Ellis, G.; Ikonomou, M.; Barrett-Lennard, L.; Addison, R. High PCB concentrations in free-ranging pacific killer whales, orcinus orca: Effects of age, sex and dietary preference. Mar. Pollut. Bull. 2000, 40, 504-515. [CrossRef]

Publisher's Note: MDPI stays neutral with regard to jurisdictional claims in published maps and institutional affiliations.

(C) 2020 by the authors. Licensee MDPI, Basel, Switzerland. This article is an open access article distributed under the terms and conditions of the Creative Commons Attribution (CC BY) license (http://creativecommons.org/licenses/by/4.0/). 